\title{
Evaluation of the Quality of Open Public Space in Addis Ababa, Ethiopia
}

\author{
Gebrechristos Nuriye (Ph.D)* \\ Hawassa University, Institute of Technology, P.O.Box 05, HUMC, Hawassa, Ethiopia \\ Daniel Lirebo (Ph.D) \\ Ethiopian Civil Service University, College of Urban Development and Engineering
}

\begin{abstract}
Urbanization history tells us that the public open space first was observed in Greek where Agora served as central market for the community to assemble, debate, and converse diverse opinions (Madanipour, 2003:194), (Larbi Touaf and Soumia Boutkhil(ed)., 2008). Thus, public spaces are part of urban structure, where space and societies are in the dynamic harmony of historical changes. This research is conducted in selected sub-cities of Addis Ababa. The results have illuminated importance of open public spaces in one hand and disclosed how existing open public spaces are deteriorating. The problem is a manifestation of unplanned development of the city whereby the city has experienced haphazard and organic development. The evaluation of the quality of public open spaces in study area is done in view of internationally recognized standards. Concurrent mixed research method is followed employing qualitative and quantitative research approaches. Sample size was scientifically determined. Data analysis was done using different statistical tools. Study results have shown that significant number of open spaces exist in the city with significant size though their performance is reported unacceptably poor. Certain open spaces were found to be in excellent conditions but inaccessible. Conversely certain public open spaces are found in poor condition but they are openly accessible for public use. Conclusions are drawn from study results and recommendations are specified accordingly.
\end{abstract}

Keywords: Open Public Spaces, Quality, Accessibility

DOI: $10.7176 / \mathrm{CER} / 12-10-01$

Publication date:October $31^{\text {st }} 2020$

\section{Introduction to the Study}

Greek Agora is historically among the first quintessential open public spaces in ancient urban history whose central function serving as a central market, though later served as a place of assembly for the town's people (Madanipour, 2003:194). This historically tells us that open public spaces are taken as part of urban structure, where space and societies are in the dynamic harmony of historical change. Notwithstanding historical perspectives, it should also be called that new types of public spaces are emerging around the world and old public space typologies are being resurrected and retrofitted to contemporary needs. There has been a growing demand and resurgence in the investment, and use of, existing and new pedestrian-oriented streets, squares, plazas, and other traditional types of open public spaces in urban areas. Not only availability but also quality of open public spaces is demanding in today's urban planning and design projects around the world. As to Commission for Architecture and the Built Environment (CABE Space, 2004), high quality public spaces are essential features of successful neighborhoods where people want to live, work, play and invest. Experiences from many countries show that quality urban open public spaces provide environmental, social and economic benefits to communities in the world. Since open public spaces constitute mainly green spaces, they provide the environmental, social and economic benefits not only to the present communities but also to the future generation with little management and maintenance costs.

\section{Background of the Study}

This study evaluates quality of open public spaces in Addis Ababa, Ethiopia. Addis Ababa is administrative, political and socio-economic capital of both Ethiopia and Africa. The city is characterized by high level of primacy being more than ten times compared to the second populated city of the nation. Besides the existing physical and aesthetical status of the city is not attractive enough and welcoming for its residents in its urban settings. The study attempts to evaluate the quality of open public spaces considering space attributes as defined using the key attributes of quality as agreed in most of related researches. The city is facing tremendous environmental, social and economic problems associated with lack of appropriate open public spaces, poor management and planning defects. Though Ethiopian National Urban Green Infrastructure Standard suggests authorities to allocate 30\% for green areas and shared public use in their urban land management plan, the reality on the ground reveals that urban spaces are congested by buildings and other structures.

There are very few formally organized open public spaces found in the town which account only for less than $5 \%$ from the total land use. It is important to note that the growth of Addis Ababa is without thorough planning intervention as the city centers composed of poor spatial qualities of open public spaces and high percentage of 
ground coverage by dense commercial and mixed use built-forms. Built-up area ratio/BAR/ in the old and central part of the city exceed $90 \%$ coverage. Besides, more than $65 \%$ of the central part of Addis Ababa is condensed with slum neighborhoods (UN-Habitat, 2015). The current situation shows that the central part of the city is more or less in the state of rejuvenation as part of Brownfield Development. But the evidence shows that less attention has been given to develop adequate open public spaces in the redevelopment areas. Therefore, this research is intended to evaluate the quality of open public spaces which is not done before and considered as a research gap. The study objective is to evaluate the quality of public open spaces in Addis Ababa based on scholarly recognized standards, the results from the study are believed to benefit stakeholders of the city in general and Beautification Office, Urban Planning Commission of the City, and the Municipality in particular regarding quality issues. Besides the outputs of the research will add to the body of knowledge so that the document will be used as reference by researchers who need to study on similar areas.

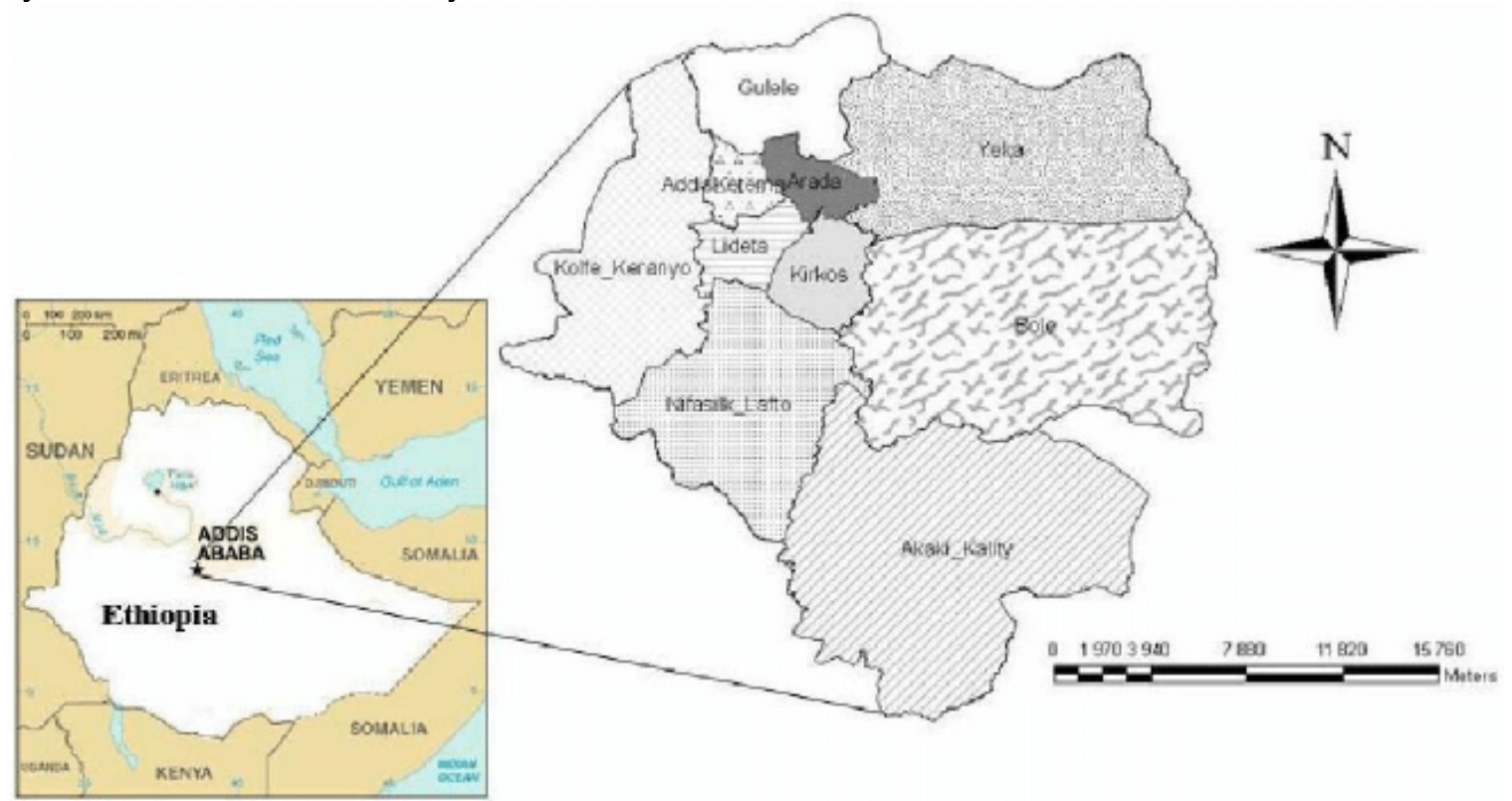

Figure 1: Location Map of Addis Ababa, Ethiopia

Source: Fikirte Demissie, etal (2015) Addis Ababa

\section{Conceptualizing Open Public Spaces}

Open public spaces are diverse in their nature. For instance the streets we pass on the way to school or work, the places where children play, places we encounter nature and wildlife, the local parks, sport grounds, and so on (CABE, 2004, p.1). Streets, squares and parks of a city (leisure green spaces) are public open spaces that form a city fabric and its character. Such spaces are often considered as green nucleus or breathing space of the city that gives form to the flow of human exchange. For instance, scholars agree that designed outdoor area are taken as open public spaces (Aljabri H., Smith H., 2013). Hence most of the time "Outdoor space" and "public open spaces" are used interchangeably. But the outdoor spaces selected in this study focuses on leisure places that found on the streetscape at the edge or in front of buildings. About such type of outdoor spaces, literatures agree that "many celebrated pedestrian environments have streets and buildings so as to create "outdoor rooms". Recently, there have been considerable rising concerns regarding the significant value of public space. The provision and the quality of public open space has climbed to the top of political and policy, social and environmental agenda of qualities (Carmona M., Heath, T., Oc T. \& Tiesdell, S. ,2003), Carmona, M. (2010). Studies show that good plan of open public spaces with all typology and hierarchy is a good mechanism to fulfill the attributes of quality open public spaces and in turn the occurrence of those attributes increase the outdoor activities.

\section{Measures of Quality of Open Public Spaces}

Contemporary open urban public space planning models, while being concerned with questions like how much, what type of and where open space should be provided, reveal that quantitative parameters (e.g. population size, spatial location and distance) are the most common measures utilized to determine open space access. Beyond quantitative standards, park system model emphasizes proximity to users and the variety of user experiences. Therefore, this model is the one which have high relation with quality of open public spaces because it is concerned about proximity and variety of experiences of users which explain quality of open public space. 


\subsection{Principles to Good Quality Public Spaces}

It is very important to know that the principles of good quality public open spaces are the destinies of urban design and planning. The principles are adopted from Quality Public Spaces Sub Group: Leeds Chamber Property Forum (2008) to suggest the stakeholders after intensively evaluating study places, benchmarking the principles and the quality measurements. So the principles to good quality open public space stated as providing a context and venue for social interaction, design primarily for the pedestrians, design the space as 'an outdoor room', create a clear and lively relationship between indoor and outdoor uses, cater for different users, provide an inclusive not exclusive place, plan a 24 hour space, Key elements must be robust and attractively designed, provide options for shade, shelter and security, not one space but many, ensure the space becomes of the existing urban hierarchy.

\subsection{Measuring the Quality of Open Public Spaces}

The UN habitat relates civility and open public spaces in such a way that quality of open public spaces can lead to civilian behavior and civilized behavior can lead to quality public spaces. In agreement with other works, UN Habitat stated that public space is the banner of urban civility (UN habitat, 2015). Qualities of open public spaces are highly related to the physical amenities, the activities, accessibility condition, the location characteristics of open public spaces and the surrounding land uses that supports the activities developed in public plaza and that will influence in their capacity to promote social interaction, livability, and comfort. Studies revealed that more than 1000 urban public spaces in different countries around the world have shown that four main factors as effective factors to evaluate quality of any urban open public spaces. They are Access and linkage, Comfort and image, uses and activities and Sociability (Vahid Bigdeli Rad and Ibrahim Bin Ngah, 2014).

The purple color in the diagram (in which land mark is placed) is a certain public square that is available in a study town. So, it is possible to evaluate that place according to the four attributes in the green box. In the yellow box next to green are an intangible of qualitative aspects by which to judge a place, the next outer red boxes show the quantitative aspects (variables) that can be measured by statistics. These four criteria are applied in this research and details are discussed below as part of operationalization framework in this research.

\subsubsection{Accessibility and Linkage}

Accessibility and linkage is given due consideration in this research among the four quality of open public spaces, since the dimension of accessibility is not determined by only in quantity (per capita) but also it can be determined by proximity (distance), the variety of user experiences and other social factors as different study revealed. Therefore, as a UN habitat report implied, the potential of open public spaces to fulfill its role of equity can best be fulfilled by correcting imbalances in the supply, quality and distribution of public spaces in different sections, neighborhoods and settlements of the city/town. This is why public space surveys have to cover the whole urban area (UN habitat, 2015). According to the Project for Public Space (PPS), it is possible to judge the accessibility of a place by its connections to its surroundings, both visual and physical. A successful public space is easy to get to and get through, it is visible from a distance and up hills.

In addition to linkage, another important quality of open public space joins linear parks, road reserves, playing fields, parks, allotments, private gardens, buffer planting and surface drainage corridors. Greenways can be created to run through or alongside linear elements such as natural streams, wooded belts or canals and connects with parks and footpaths in nearby neighborhoods. These can plug into neighborhood streets that have cycle routes, reduced car levels and mature tree planting - creating a network of what the city of Vancouver calls 'Green WaysPublic Ways'. To bring this network, the $400 \mathrm{~m}$ or 5minute walkable catchment radii focused on neighborhood focal points forms the starting principle for network design (Llewelyn-Davies, 2007).

\subsubsection{Comfort and Image}

According to PPS, a space which is comfortable and presents itself well, that means a place which has a good image is a key to its success. Comfort includes perceptions about safety, cleanliness, and the availability of places to sit, walking and provide favorable image of community life. Comfort and image is related to how the public space is physically arranged. As a result quality of the open public spaces can be easily recognized and attract many people to the public space. 


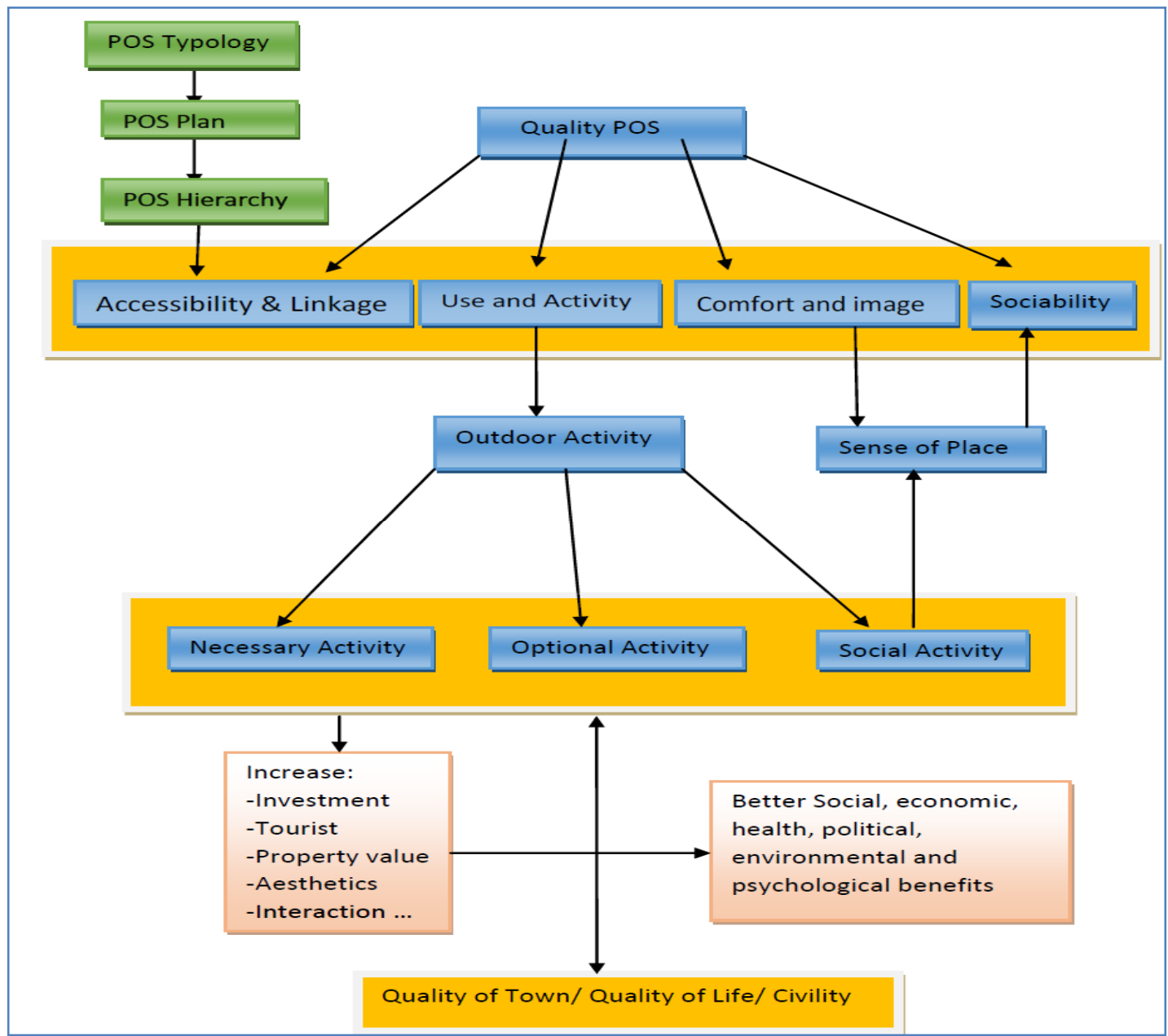

Fig 2: Diagram Illustrating the Role and Relation of Quality Open Public Space with Quality of Town Source: Schematic Diagram Developed by Researchers, 2018

\section{Methods and Resources}

The study with concurrent mixed approaches follows the case study strategy. The government offices are selected from target Sub Cities to administer FGD and key informant interview. The target public offices are 1) Urban Planning Office 2) Office of Urban Greenery and Beautification and 3) Youth and Sport Office. Three focus groups from these three target public offices each with 12 participants (a total of 36 participants) comprising professionals and officials are selected for discussions. Besides, a total of 9 officials ( 3 from each target sites) were interviewed. On the other hand 200 participants from each study area totaling 600 community members/residents from the inner city, the intermediate surrounding and the suburb were taken in proportion. Of which 486 participants responded and returned the questionnaire. Besides 1 FGDs in each study area (totally 3 FGD) with 12 participants totaling 36 participants are participated. Totally six FGDs each with 12 participants totaling 72 participants from the three targets. Matrix rating technique in SPSS were utilized to compare results from each case analysis in reference to identified open public space quality indicators. To ensure validity and reliability of the study all ethical considerations of the research were respected. Data from diverse sources were triangulated using method wise and subject matter wise.

\section{Results and Discussions}

Addis Ababa is among the fastest growing urban areas in the world. Since 1970, the population has increased by nearly threefold. However, the spatial expansion of the urban area has been much greater than the population growth. The earliest available Google Earth satellite photos (1973) indicate that the urban land area (continuous urban development) has expanded over 12 times. Thus, the urban spatial expansion has been at least four times that of the population since the early 1970s (Figures 4.2). 


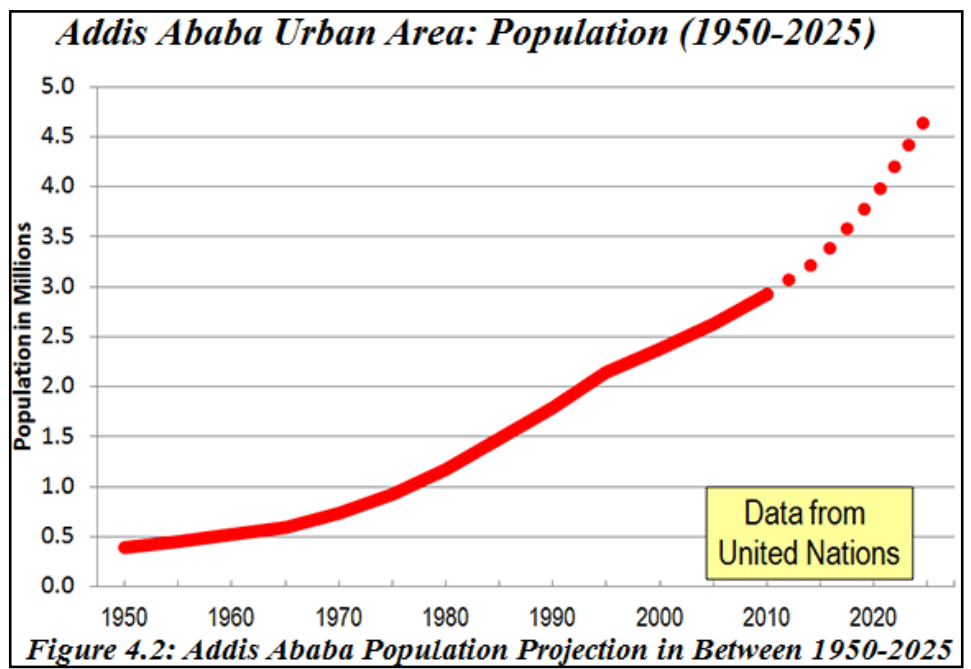

Since 1973, the urban population density of Addis Ababa has declined almost three quarters, from approximately 75,000 per square mile or 29,000 per square kilometer to 20,000 per square mile or 8,000 per square kilometer. Addis Ababa represents yet another example of the counter-intuitive reality of growing urban areas simultaneously becoming less dense, because population growth occurs, generally less dense periphery in an organic city areas.

Major government offices and cultural facilities are in the inner area, such as the Parliament, the prime minister's residence, museums, the residence of the primate of the Ethiopian Orthodox Church (Coptic), the most important cathedral, Holy Trinity, in which former Ethiopian leader Haile Selassie is buried, as well as the Catholic Cathedral and the largest Mosques.

\subsection{Response Rate}

A total of 600 survey questionnaire was initially designed and distributed to respondents according to the initial plan. Of which 486 (81\%) questionnaires were filled and returned back to researchers. Only properly filled and returned questionnaires were considered for further analysis.

\subsection{Demographic and Socio-economic Characteristics of Respondents}

\subsubsection{Age, Marital Status and Family Size}

The study results have shown that about $88 \%$ of total participants are in age category of more than 25 years. Of which more than 52 participants are in age group of more than 35 years which indicates that participants are matured enough to respond questions in responsible way. Nearly $80 \%$ of the total respondents are married and only about $12 \%$ of respondents were reported as single. Share of divorced and widowed respondents is less than $10 \%$. Family structure is among important variables treated under this study. The result has shown that about $80 \%$ of the total respondents have a family size of 6 and less which is not much deviant from census result. However, about $11 \%$ of research participants reported that their family size is more than 9 which is very large compared to Central Statistical Agency average (5 members in family) of the nation (Table 1).

\section{Table 1. Description of Selected Demographic Variables of Respondents}

\begin{tabular}{l|l|l|l|l|l|l|l|l} 
Age & No. & $\%$ & Marital Status & No. & $\%$ & Family Size & No. & $\%$ \\
<18 Years & 16 & 3.3 & Single & 57 & 11.7 & $<3$ & 174 & 35.8 \\
18-25 Years & 43 & 8.8 & Married & 385 & 79.2 & $3-6$ & 211 & 43.4 \\
26-35 Years & 173 & 35.6 & Divorced & 18 & 3.7 & $6-9$ & 45 & 9.3 \\
> 35 Years & 254 & 52.3 & Widowed & 26 & 5.3 & $>9$ & 56 & 11.5 \\
Total & 486 & 100.0 & Total & 486 & 100.0 & Total & 486 & 100.0
\end{tabular}

Source: Field Survey, 2018

\subsection{Evaluation of Quality of Open Public Spaces}

\subsubsection{Availability of Open Public Spaces by Current Residential Area}

Availability, quality and access of public open spaces are becoming among core measures in modern urban planning efforts. Poor quality and the existence of few open public spaces in the study area are among deficits in the development of the city. The new office for Urban Greenery and Beautification is very recent and does not have much of the plans and strategies lined out yet. According to the master plan the open spaces are categorized in to local, district and city level open spaces. 

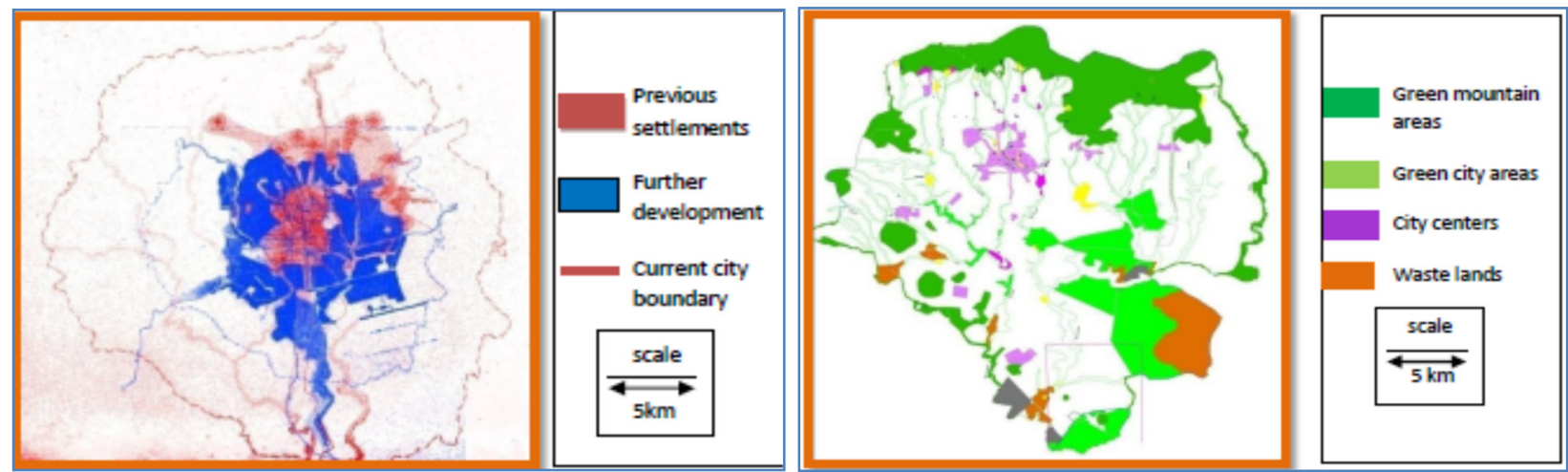

Figure 3: Development of Addis Ababa

Source: Ministry of Works and Urban Development (2009)

Research participants asked if the open public spaces are available around their residences and they reported accordingly. From total respondents, $84 \%$ of them agreed about availability of at least one type of open public spaces and only $16 \%$ of research participants said that open public spaces were not available in their residential areas. When spatial distribution is evaluated, about $34 \%$ of respondents reside in Bole Sub-city, Woreda 7, and $27 \%$ of respondents in Yeka Sub-city Woreda 8 . Of which $33 \%$ and $18 \%$ of respondents confirmed availability of open public spaces around their residential areas respectively. Kirkos Sub-city Woreda 7 and 8 constitute $36 \%$ of the total participants from which $29 \%$ confirmed the presence of public open spaces around their residences (Table 2).

Table 2. Availability of Public Open Space by Current Residential Area

\begin{tabular}{|l|l|l|l|l|l|l|l|}
\multicolumn{2}{|l}{ Availability of Public } & \multicolumn{2}{l|}{ Sub-Cities/Current Residential Area } \\
\multicolumn{2}{|l|}{ Open Space } & Bole W. 7 & Yeka W. 8 & Kirkos W. 7 & Kirkos W. 8 & Others & \\
Yes & No. & 162 & 88 & 89 & 54 & 15 & 408 \\
& $\%$ & 33.3 & 18.1 & 18.3 & 11.1 & 3.1 & 84.0 \\
No & No. & 4 & 44 & 3 & 27 & 0 & 78 \\
& $\%$ & 0.8 & 9.1 & 0.6 & 5.6 & 0.0 & 16.0 \\
Total & No. & 166 & 132 & 92 & 81 & 15 & 486 \\
& $\%$ & 34.2 & 27.2 & 18.9 & 16.7 & 3.1 & 100.0
\end{tabular}

Source: Field Survey, 2018

Desk review results have shown that Open Public spaces in Addis Ababa are categorized into field crop, vegetable farm, public recreational parks, riparian vegetation, plantation forest, institutional forest (mixed forest), street plantation, and grassland. Assessment of the green space of Addis Ababa based on aerial photo taken in 2011 showed that field crop constitutes about $65 \%$ of the total green space of the city covering 14578 ha of land. However, this green space has been reduced to 9835 ha in 2014; a loss of 5476 ha, largely due to conversion of the field crop land to residential (condominium), manufacturing and storage land uses.
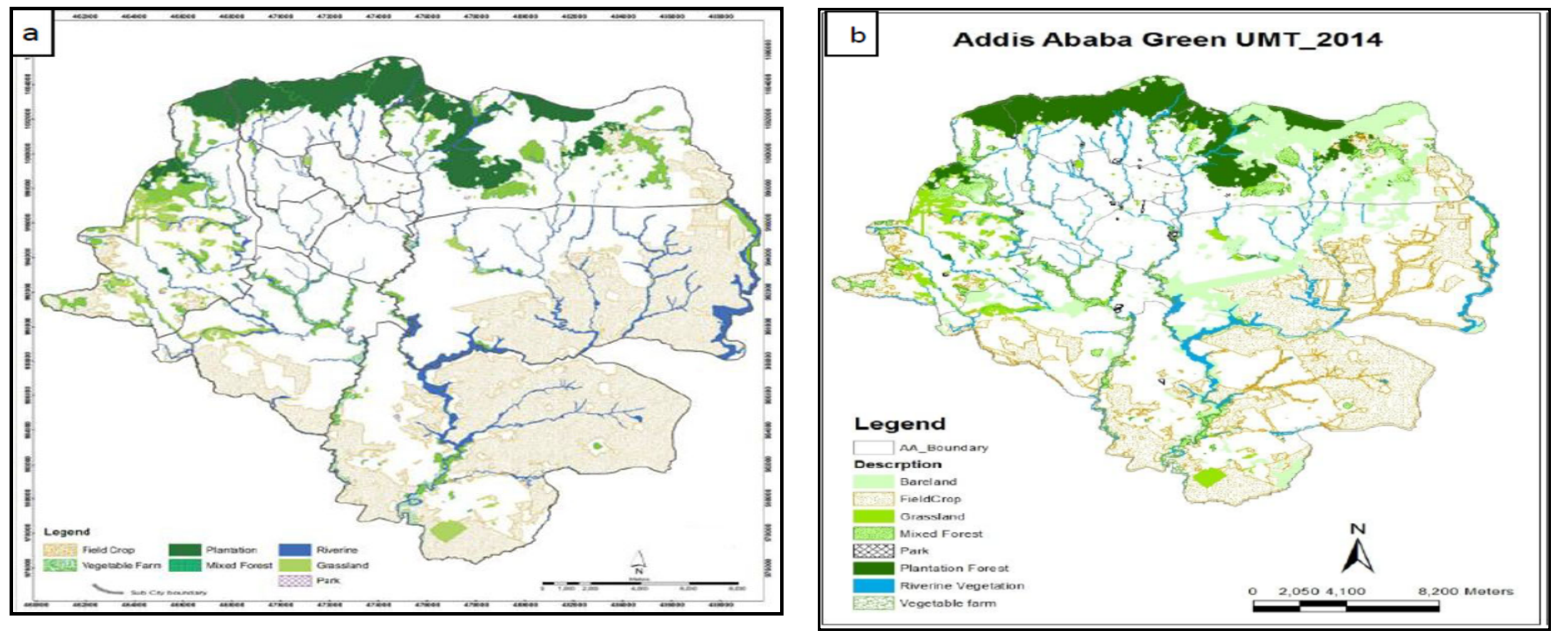

Figure 5: Map of Addis Ababa Showing Open Green Spaces, (a) in 2011 and (b) in 2014 


\subsubsection{Existing Quality and Reasons for the Current Level of Quality of Public Open Spaces}

Quality of urban open public spaces is the reflection of provisions of the city's plan. Addis Ababa Master Plan has been formulated in 1986 by the City Administration in cooperation with the Italian Government. The master plan focuses on various development topics such as population, agriculture, industry, transport, public amenities \& utilities, housing, town and landscape. The master plan was prepared to guide the city for 20 years. The Master plan was composed of Regional, Metropolitan and Urban levels growth models. It aims at accommodating the city growth through upgrading, infill, densification and expansion.

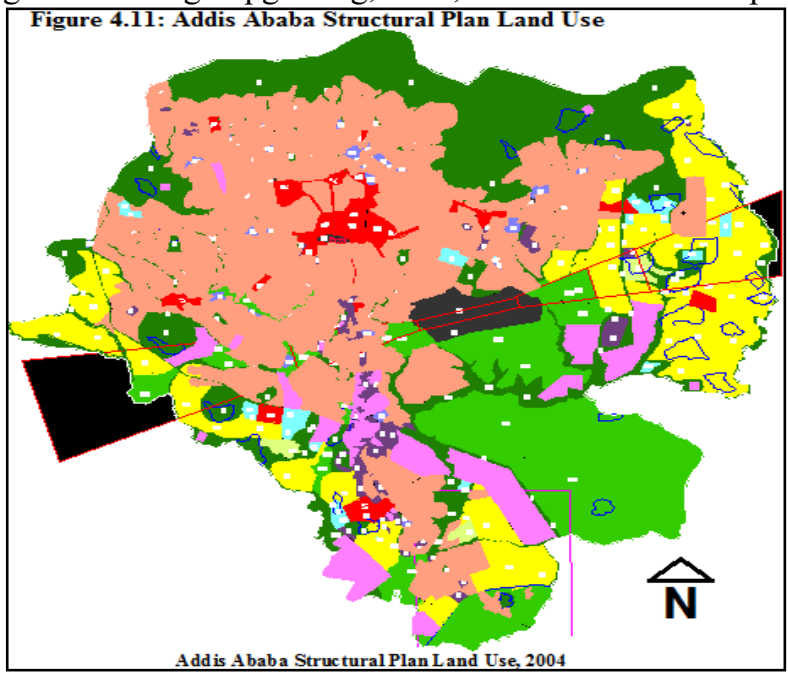

Respondents evaluated the quality of open public spaces. About $63 \%$ of respondents said that quality of existing open public spaces was bad whereas about 34\% judged them as fair both amounting 97\%. Only about 3\% of respondents confirmed that existing quality of open public spaces are in good condition. Poor management by government is reported as the most important contributing factor by accounting more than $60 \%$ of the responses. It was significantly reported that the community contribution was less accounting $30 \%$ of the total and reported as the contributory factor for bad quality of public open spaces. (Table 3 ).

Table 3. Respondents Opinions about Existing Quality and Reasons for Current Level of Quality of Public Open Spaces

\begin{tabular}{|l|l|l|l|l|l|} 
Existing Quality of POS & No. & $\%$ & Reasons for Bad Quality & No. & $\%$ \\
Good Quality & 16 & 3.3 & Poor Management by Government & 298 & 61.3 \\
Fair Quality & 165 & 34.0 & Lack of Attention by the Community & 146 & 30.0 \\
Bad Quality & 305 & 62.8 & Not Applicable & 42 & 8.6 \\
Total & 486 & 100.0 & $\ldots$ & 486 & 100.0
\end{tabular}

Source: Field Survey, 2018

When the case of Meskel Square in Woreda 7 Kirkos Sub-city is evaluated, the open space has certain unique characters as:

- It is the first urban open space to be designed for the purpose.

- It is the only place recognized by the city administration as plaza.

- It is found in the center of the city and is easily accessible from any part of the city.

- It is the largest Amphitheatre in the city.

- It is considered as the only open gathering place when the city hosts international events. 


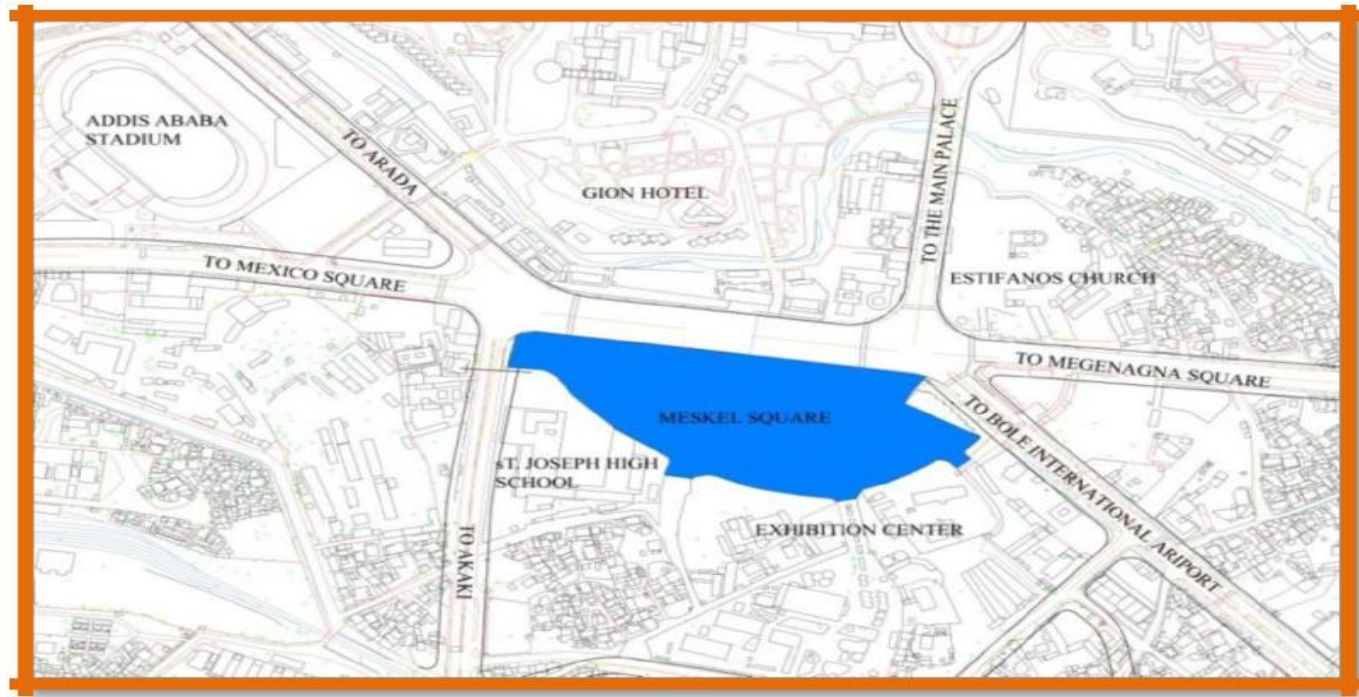

Figure 7: Meskel Square and Its Surrounding

Meskel Square has political significance because different political performances are taking place in it. Even the name of the square was what they called Revolutionary Square which means Abiyot Square and later changed to Meskel Square. Social, political, economic and cultural performances, ceremonies and occasions, etc are being hosted on the square. The yearly political festival on the square is the May 28 celebration of the ruling party signifying the day the current took power. There are also other political festivals which are mainly the gathering of people called by government officials. As has been done in previous periods, the government uses this place as a communication place with the people. Other major gatherings are during election periods. The square is used by the government as well as opposition parties during this time to pass their message to their supporters. Thus, the square has now become a symbol of democracy which is the goal of the ruling party.

The other case is Africa Parks which is found in Kirkos Sub-city of woreda 8. The park is modern one compared to its counter parts. Though the park satisfies many aspects of quality, it does not satisfy a component of accessibility which is among one of quality measures. Studies show that an inaccessible open public space in the built environment gives an individual with unpleasant feeling and bad spiritual and psychological comfort and had unique geographic and poor socio-economic characteristics. Many residents living around the Africa Park and informants have expressed their view as the park is physically the remarkable open space in Addis Ababa. But it is fenced and protected from the communities and is inaccessible.

Fig 5.5: Africa Park: Physically Good Quality of Open Public Spaces but Inaccessible

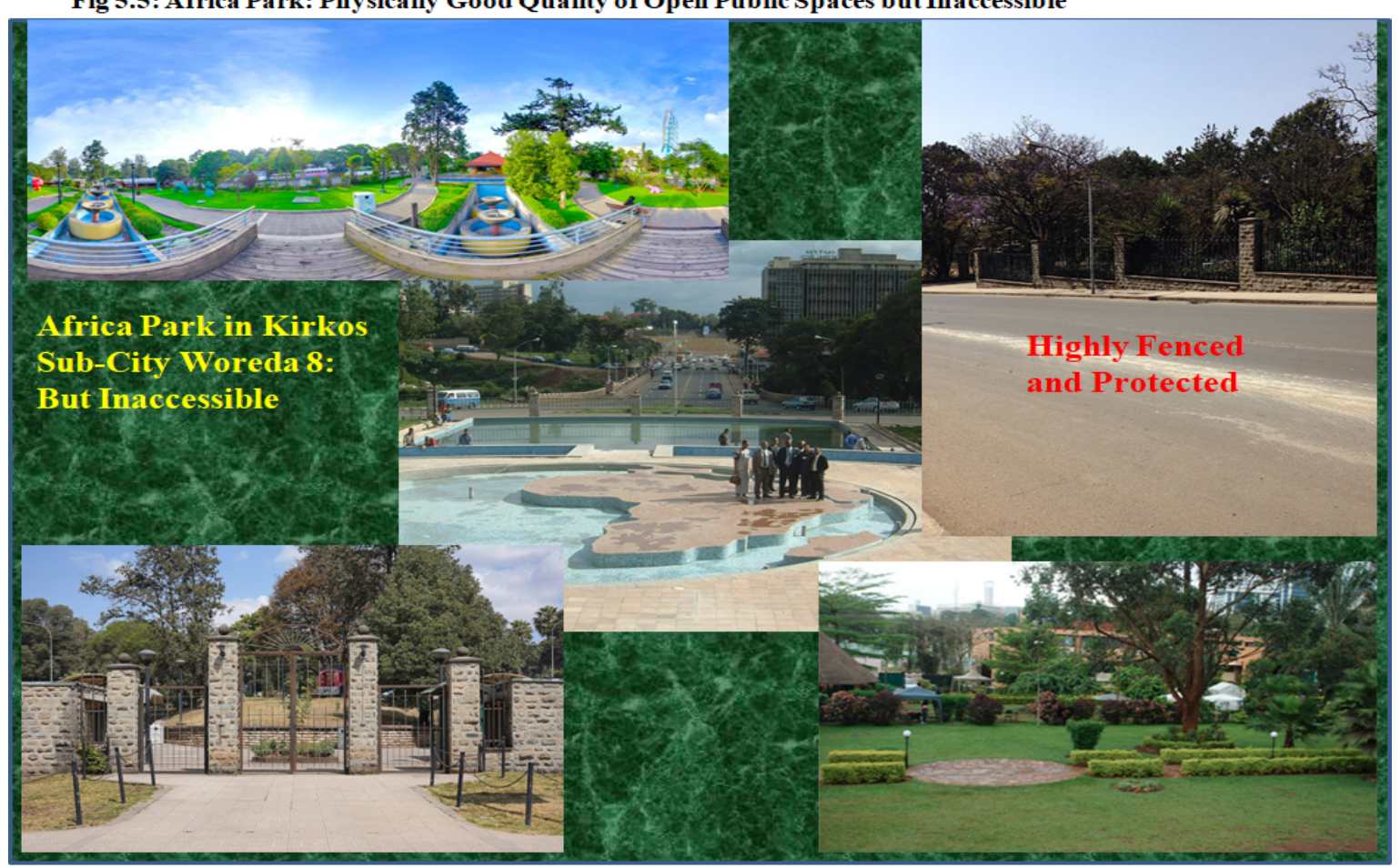




\subsection{3. $\quad$ Existing Quality of Open Public Space by Types of Open Space}

As the uses of open spaces are varied, their quality is also reportedly varying from one type of open public spaces to the other. About $63 \%$ of research participants reported that quality of open public spaces is bad whereas only $34 \%$ of participants said as fair. Only $3 \%$ of the total respondents said that existing open public spaces are in good condition. As discussed above, $57 \%$ and $25 \%$ of the total participants were reported that they were using neighborhood parks and pocket spaces both accounting for $82 \%$ of the total respectively. However, $53 \%$ from $57 \%$ reported that quality of neighborhood parks as bad. From the total users of pocket spaces, $23 \%$ out of $25 \%$ reported the quality is fair (Table 4).

Table 4. Existing Quality of Public Open Space by Types of Open Space

\begin{tabular}{|c|c|c|c|c|c|c|c|}
\hline \multicolumn{2}{|c|}{$\begin{array}{l}\text { Existing Quality of Public } \\
\text { Open Space }\end{array}$} & \multicolumn{5}{|c|}{ Type of Open Space } & \multirow[t]{3}{*}{ Total } \\
\hline & & Neighborhood & Pocket & Small Green & Play & Others & \\
\hline & & Park & Space & Space & Ground & & \\
\hline \multirow[t]{2}{*}{ Good Quality } & No. & 0 & 0 & 0 & 16 & 0 & 16 \\
\hline & $\%$ & 0.0 & 0.0 & 0.0 & 3.3 & 0.0 & 3.3 \\
\hline \multirow{2}{*}{ Fair Quality } & No. & 19 & 112 & 7 & 3 & 24 & 165 \\
\hline & $\%$ & 3.9 & 23.0 & 1.4 & 0.6 & 4.9 & 34.0 \\
\hline \multirow[t]{2}{*}{ Bad Quality } & No. & 257 & 9 & 6 & 0 & 33 & 305 \\
\hline & $\%$ & 52.9 & 1.9 & 1.2 & 0.0 & 6.8 & 62.8 \\
\hline \multirow[t]{2}{*}{ Total } & No. & 276 & 121 & 13 & 19 & 57 & 486 \\
\hline & $\%$ & 56.8 & 24.9 & 2.7 & 3.9 & 11.7 & 100.0 \\
\hline
\end{tabular}

Source: Field Survey, 2018

6.3.4. Quality of Public Open Space in the Neighborhood

The fact that there exist many measures of quality, certain variables related to quality elements are discussed based on opinions from discussants and survey respondents. Of which ground coverage or built-up area ratio customarily named as BAR are among important components measure of quality of public open spaces. As illustrated on the figure 5.11 below, the percentage of ground coverage in the study neighborhood is overwhelmingly above $85 \%$ that means the ground coverage from 81 to $90 \%$ consisted major proportion of the study settlement, highly occupied by dense built-forms. The figures 5.10 and 5.11 also unveil that the existence of close distance between housing structures and high ground coverage, there are no outdoor spaces to children to play, no amenities, and family members to recreate in the greenery spaces around the building structures.

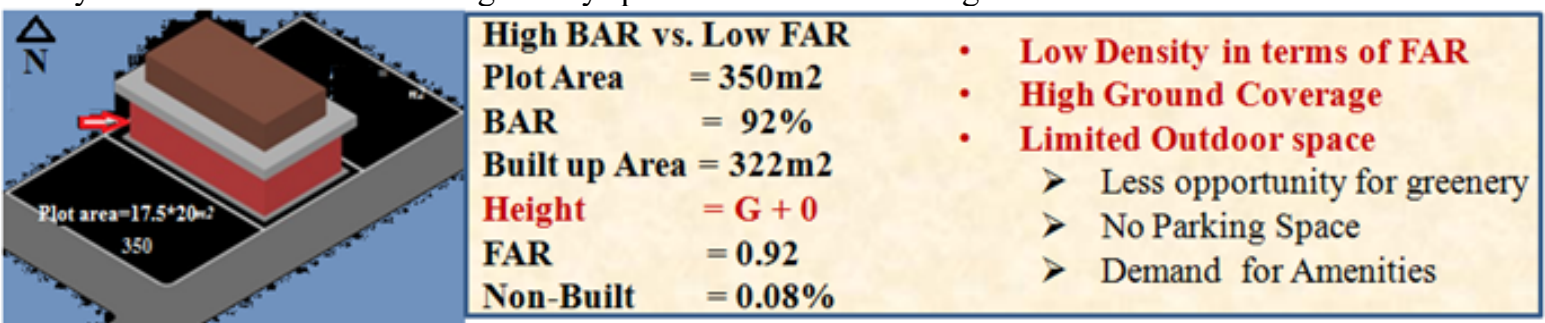

Figure 5.10: Typical Example of high Ground Coverage exceeding the thresholds, no spaces for outdoor, amenities

It would create difficulties for the provision of amenities in the plot as parking spaces. It exerts severe challenges in the private quarters and shortage of quality urban spaces in the neighborhood. It is also important to note that Ground coverage has been used as a measure of spatial coverage of buildings. It provides a sound basis for analyzing "mass" of built spaces in relation to size of plots.

Due to the rapid rate of the on-going piecemeal redevelopment processes coupled with laxity in development control many buildings have been built beyond recommended coverage $(<50 \%)$ (Figure 5.11$)$. Ground coverage of up to $110 \%$ has also been observed. This means that buildings in those plots have been built beyond plot boundaries therefore blocking partly or wholly all sides, front and rear set-backs. Measurements and observation studies in the same blocks for the year 2014 reveals increasing trends in coverage (Figure 5.11). 
The ground coverage in Woreda 8 Yeka Sub-City indicates that only 1 out of 26 buildings conformed to the building requirements of $50 \%$ plot coverage or not exceeding $50 \%$. Although it is understandable that there is need of maximizing the use of land especially in prime areas like Woreda 8 Yeka Sub-City, excessive ground coverage caused by building extensions and reconstruction of buildings often compromise livability attributes. Since many houses have exceeded the recommended $(<50 \%)$ ground

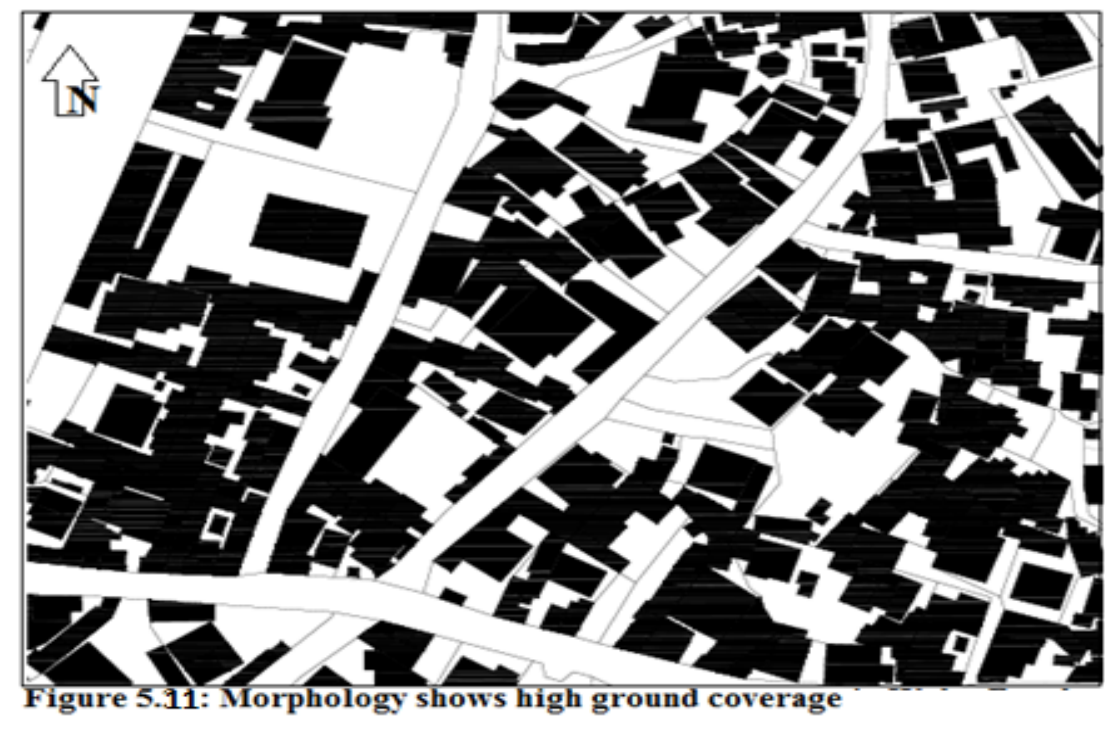
coverage, in case of fire accident in one building it is likely to spread to the adjacent ones due to inaccessibility and absence of spaces for circulation.

When residents of Kazanchis were asked to assess their settlement, the majority expressed discontent with issues of security, outdoor open spaces, circulation spaces and many pointed out the aspect of built-up density. The congested streets with street vendors and hawkers have resulted into pick-pocketing and other vices. Poor drainage is also a result of increased ground coverage with a poor drainage system resulting in storm water stagnation along the streets. The water supply issue is related to an overloaded system that is old and can no longer suffice the present requirements. Water rationing is frequent in Woreda 8 Yeka Sub-City and water does not reach the upper floors of the newly developed high-rise condominium buildings i.e. in few newly built condominiums housing due to low pressure.

Total Floor Area Ratio (FAR) is one of indicators for quality of open public spaces. Since floor area ratio takes into consideration of the height of buildings, it has been frequently used as a tool to regulate built-up density and townscapes. It has also been used as a tool for formulating space standards for central functions of cities. Two levels have been examined in terms of floor area ratio. The first is at plot and second is at block as well as neighborhood level. Detailed measurements of floor area ratios at plot level in Kazanchis show some kind of pattern of built-form that is not evenly distributed. The majority of the buildings have floor area ratio/FAR/ ranging between 0.8 and 1.15 .

The floor area ratio is high especially when single storey houses are considered. The kind of even distribution in floor area ratio indicates that buildings have differing heights since plot size in this area does not vary considerably. With the exception of the few condominiums building that has 5 storeys, many of the buildings have a height varying from one to three storeys, when floor area ratio is considered at a block level, thereby including half the width of the surrounding streets. When floor area ratio at plot level is taken into consideration, the overall result is as high as 1.15. The high floor area ratio is a result of high-rise buildings constructed within the blocks but also the high ground coverage from the low-rise buildings. Apart from the few undeveloped plots in the blocks and an open space along Kazanchis Street space there are no spaces between buildings that can act as 'lungs' to the compact layout with high-rise buildings further blocking ventilation and lighting as a kind of poor spatial quality indicators.

Poorly managed dense environments have been associated with negative externalities of overloaded amenities and utilities, lack of spaces for playing and socializing, absence of greenery and open spaces, poor livability qualities and problems of resettlement when introducing infrastructure especially in Kazanchis consolidated settlement due to high percentage of ground coverage. As detailed in figures below, the detailed block level builtup density computation revealed that the total floor area ratio (FAR) and built-up area ratio (BAR) are nearly equal with negligible differences. These facts unveiled that the built environment is highly occupied by dense builtforms, which is being limited the probability of having adequate circulation spaces, incidental open and green spaces as well as blocking ventilation within the blocks of housing structures. 

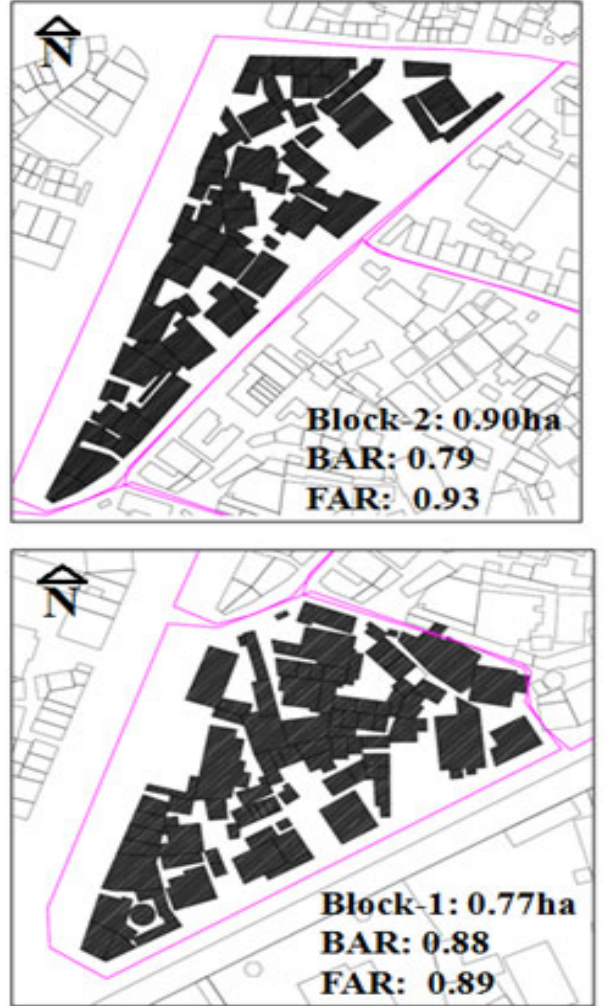
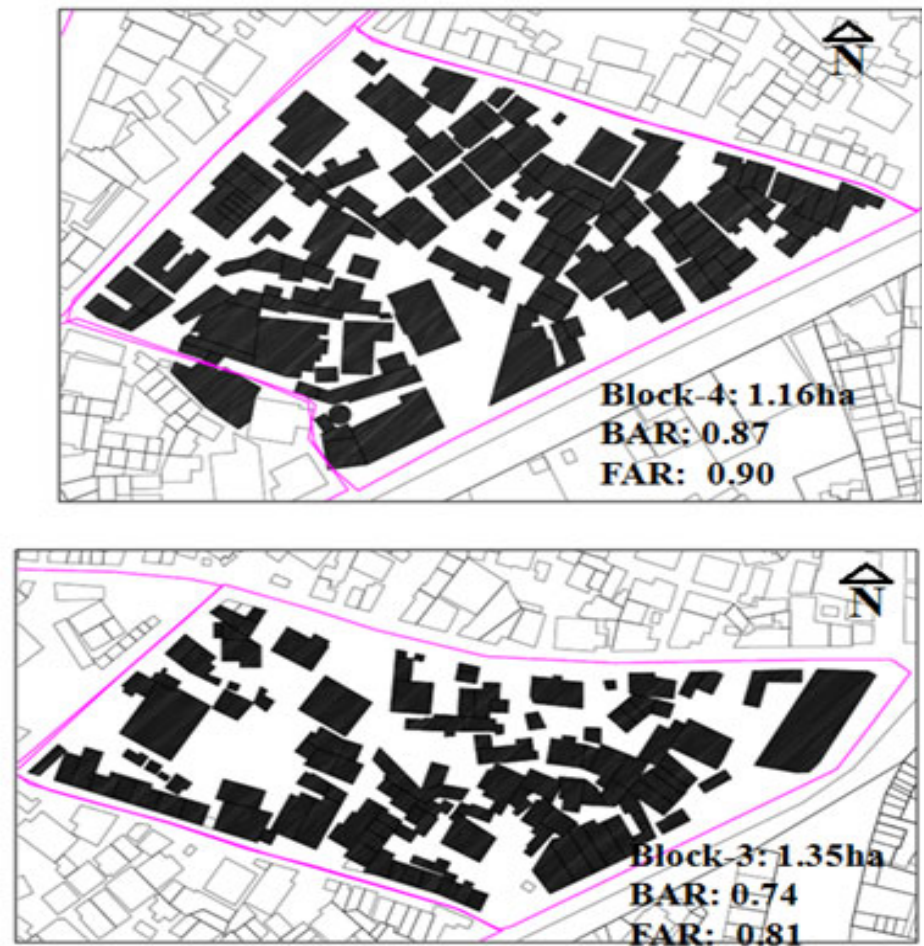

Figure 5.14 (1): Built-up Density at block level

Building Set-Backs and Open Public Spaces

Building set-backs are among important measures of quality of open public spaces. The study result have shown that encroachment of building set-backs is rampant in the study area as indicated in figure below whereby more than $50 \%$ of the buildings have front set-backs less than $0.5 \mathrm{~m}$ due to encroachments from all sides. Consequently problems associated to privacy between neighbors, property disputes, less space for daylight access and cross ventilation and air circulation as aspect of spatial quality are emerged. Standard building set-backs are important to provide open spaces for landscaping and recreation because it gives adequate room for emergency vehicles between and around the buildings, provide access for workers to deal with power, water and communication lines. Besides it provides space for regular maintenance work of the building, sallow space for vehicles to park in front of their buildings without blocking the street and improves street visibility and vehicle maneuvering.

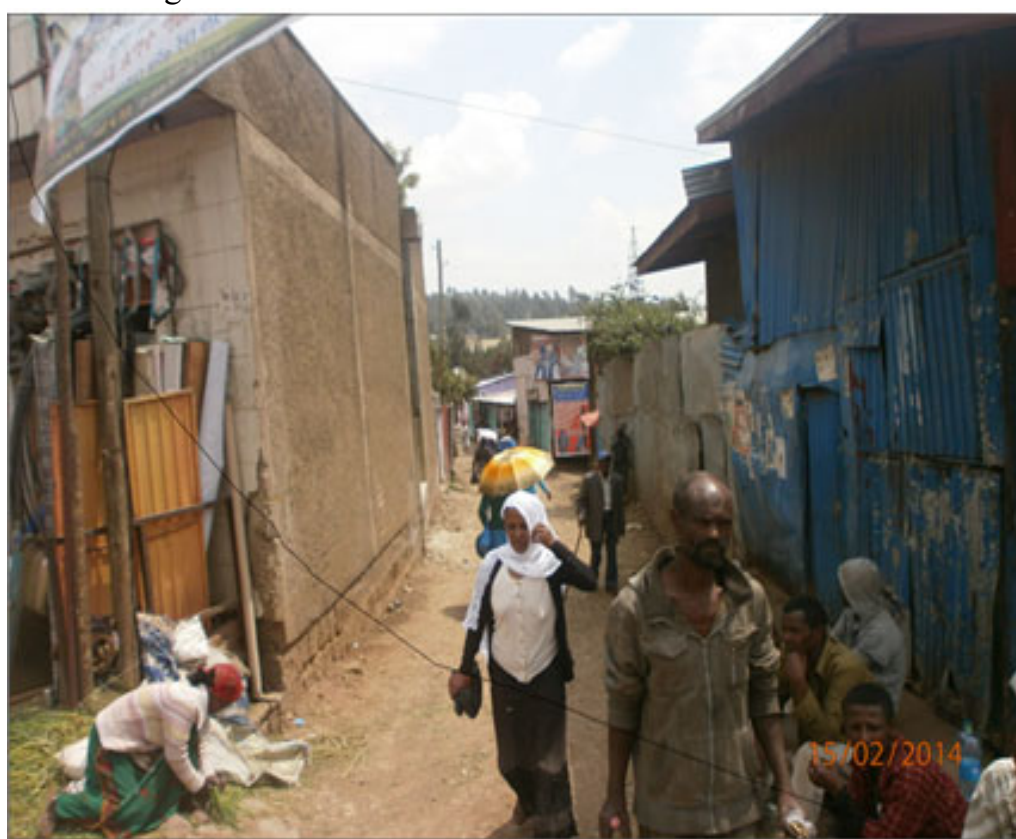

Figure 5.15 Narrow Foot Paths: Too Narrow foot Paths make walking uncomfortable and unsafe. When Two bullding enclose this narrow space due to absence of side set-backs
Encroachments are of two categories namely horizontal (front, rear and side setbacks of the buildings) and vertical set-backs (constructions of additional floor spaces above the roof level). The focus of this study is that of horizontal set-backs of the building in the study area. Though all buildings are expected to follow designs per as building bye-laws that include front, rear and side set-backs for the ground level. By-laws also constitute building height, total floor area ratio (FAR) permissible for construction and ground coverage or built-up area ratio (BAR) to provide open and green spaces with the plot area. The analyzed data unveil that people tend to construct violating the local building rules and regulations by pleading ignorance or exhibiting arrogance. 


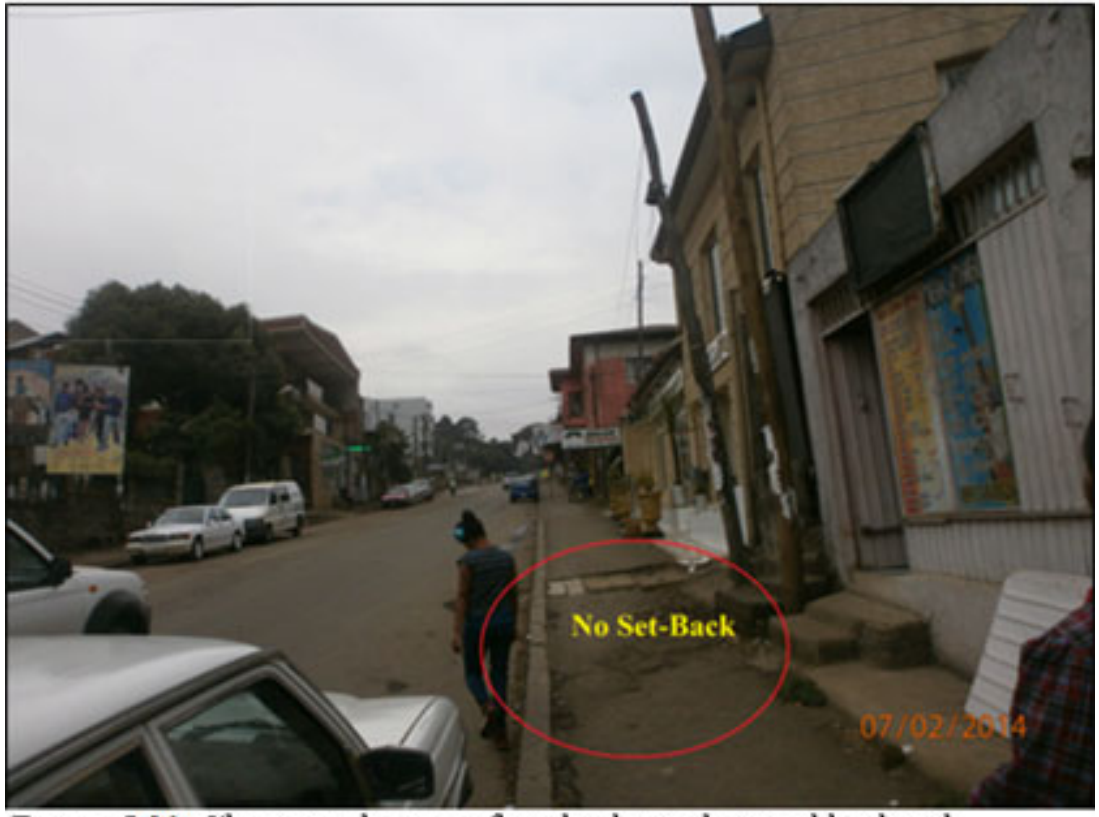

Figure 5.18: Showing absence of set-backs in the neighborhood
The figure shows that the neighborhood has no significant variations or very small in dimensions of front set-backs that can't play significant role in the safety of circulation and mobility, ventilation daylight access, street side greenery and opens spaces etc. Figure 5.18 unveil that the neighborhood has no well-planned front set-backs. Therefore, the analysis result made sure that front set-backs did not play significant role in bringing good spatial quality in the study area due to poor planning and low performances of the by-laws.

Research respondents have rated quality of public open spaces in their neighborhood. As the results have shown 375 (77\%) and $73(15 \%)$ of respondents have shown strong disagreement and disagreement respectively about quality of outdoor spaces both accounting $92 \%$ of the total. Figures for ventilation, accessibility and circulation spaces are $80 \%$ and $15 \%$ accounting for the total value of $95 \%$ for ventilation, $21 \%$ and $74 \%$ accounting for the total value of $95 \%$ for accessibility and $7 \%$ and $79 \%$ accounting for the total value of $86 \%$ for circulation spaces respectively. The values for density low built up area ratio and density high floor area ratio are $95 \%$ and $4 \%$ with a total of $99 \%$ and $18 \%$ and $81 \%$ with a total of $99 \%$ respectively (Table 5)

Table 5. Respondent Given Level of Agreement about Quality of Public Open Spaces in Their Neighborhood

\begin{tabular}{|c|c|c|c|c|c|c|c|c|c|c|c|c|}
\hline \multirow[t]{2}{*}{$\begin{array}{l}\text { Level } \\
\text { Agreement }\end{array}$} & \multicolumn{2}{|c|}{ Outdoor Spaces } & \multicolumn{2}{|c|}{ Ventilation } & \multicolumn{2}{|c|}{ Accessibility } & \multicolumn{2}{|c|}{$\begin{array}{l}\text { Circulation } \\
\text { Spaces }\end{array}$} & $\begin{array}{l}\text { Den } \\
\text { Low } \\
\text { Up } \\
\text { Rati }\end{array}$ & $\begin{array}{l}\text { ty } \\
\text { Built } \\
\text { Area }\end{array}$ & $\begin{array}{l}\text { Densi } \\
\text { Floor } \\
\text { Ratio }\end{array}$ & $\begin{array}{l}\text { yigh } \\
\text { Area }\end{array}$ \\
\hline & No. & $\%$ & No. & $\%$ & No. & $\%$ & No. & $\%$ & No. & $\%$ & No. & $\%$ \\
\hline Strongly Disagree & 375 & 77.2 & 387 & 79.6 & 102 & 21.0 & 36 & 7.4 & 462 & 95.1 & 85 & 17.5 \\
\hline Disagree & 73 & 15.0 & 75 & 15.4 & 361 & 74.3 & 383 & 78.8 & 20 & 4.1 & 397 & 81.7 \\
\hline No Difference & 19 & 3.9 & 21 & 4.3 & $\ldots$ & $\ldots$ & 44 & 9.1 & 1 & 0.2 & 1 & 0.2 \\
\hline Agree & 16 & 3.3 & $\ldots$ & $\ldots$ & $\ldots$ & $\ldots$ & $\ldots$ & $\ldots$ & $\ldots$ & $\ldots$ & $\ldots$ & $\ldots$ \\
\hline Strongly Agree & 3 & .6 & 3 & .6 & 23 & 4.7 & 23 & 4.7 & 3 & 0.6 & 3 & 0.6 \\
\hline Total & 486 & 100.0 & 486 & 100.0 & 486 & 100.0 & 486 & 100.0 & 486 & 100.0 & 486 & 100.0 \\
\hline
\end{tabular}

Source: Field Survey, 2018

Figures for security, building plot exposure, and front setbacks are $76 \%$ and $20 \%$ with the total value of $96 \%$ for security, $6 \%$ and $76 \%$ with total value of $82 \%$ for building plot exposure and $13 \%$ and $76 \%$ with the total value of $89 \%$ for front set-backs respectively. Respondent rated values for shopping, social services and facilities are 5\% and 79\% with the total value of $84 \%$ for shopping facilities, $59 \%$ and $20 \%$ with the total value of $79 \%$ for social services and facilities and $68 \%$ and $13 \%$ with the total value of $81 \%$ respectively (Table $6)$.

Exposure as quality indicator refers to the number of sides of the building or plot that are contiguous to open public spaces, amenities or street. The significance of plot exposure underlies two basic requirements. First, the requirement that plot exposure provides an opportunity for the building to have

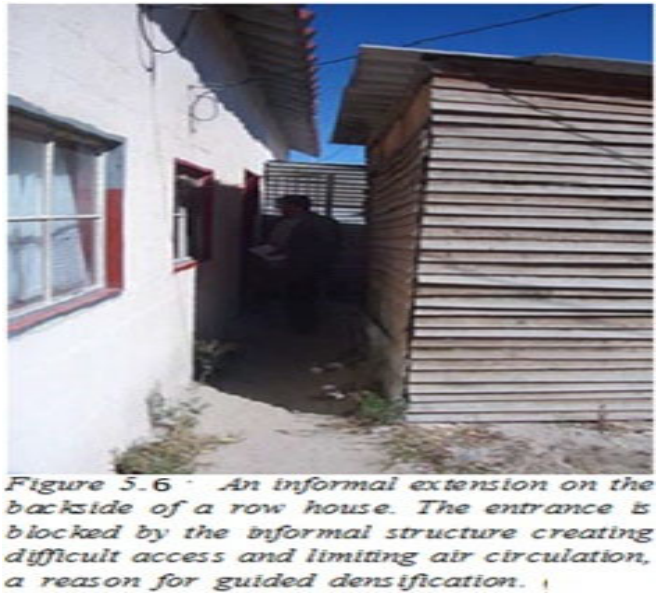


main openings to an open area. Second, is the requirement that in hot dry \& semihumid climates like Addis Ababa, plot exposure increases human comfort by providing cross-ventilation and adequate lighting. One remarkable feature in Woreda 8 Yeka Sub-City with respect to plot exposure is the fact that the original design of plot layout took into consideration the need of adequate exposure of plots. This is revealed by the provision of the rear alleyway as pedestrian access to the spaces. Two or more exposures may also allow multiple entries to different parts of the house from the street... Multiple plot exposure becomes more important when many

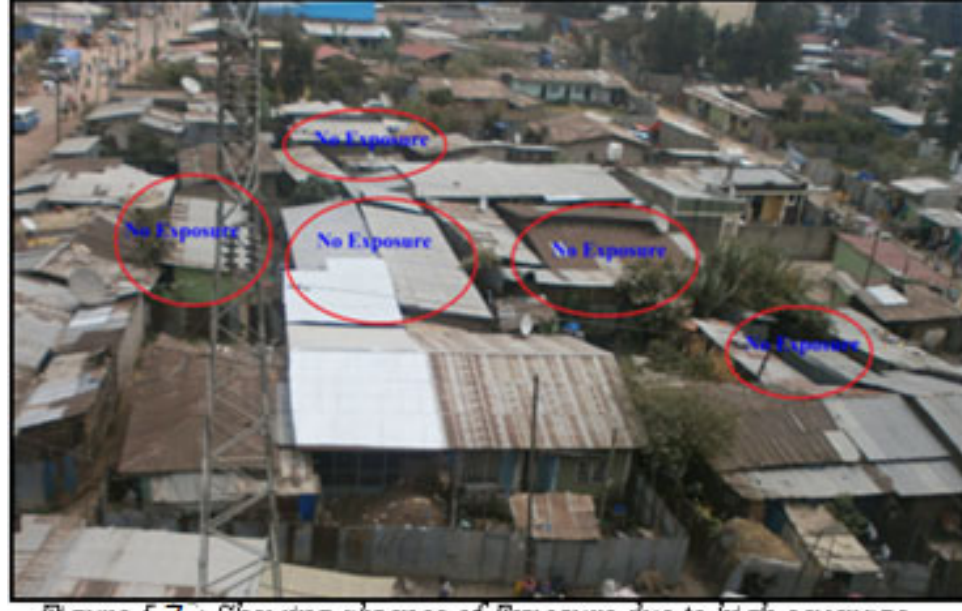

Flgure 5.7 : Showing absence of Exposure due to high coverage people share a single house or when part of the house is rented to another family or is dedicated to commercial use. Single exposure plots with only one entry reduce privacy and increase the amount of interior space devoted to circulation.

The study results have shown that certain residents seem satisfied with social contacts but highly dissatisfied in terms of accessibility of open public spaces, ventilation, security, room sizes, plots sizes, plot exposure and outdoor open spaces and degree of privacy within their housing areas. Besides, larger proportions in terms of dislikes or dissatisfaction include noise, cross ventilation, plot exposure, and outdoor open public spaces.

As seen in the figure below the internal streets inside the blocks are very narrow and have limited spaces for circulation limiting quality of open public spaces, hence spatial qualities are related to the space usability; safety and security, possibility to use

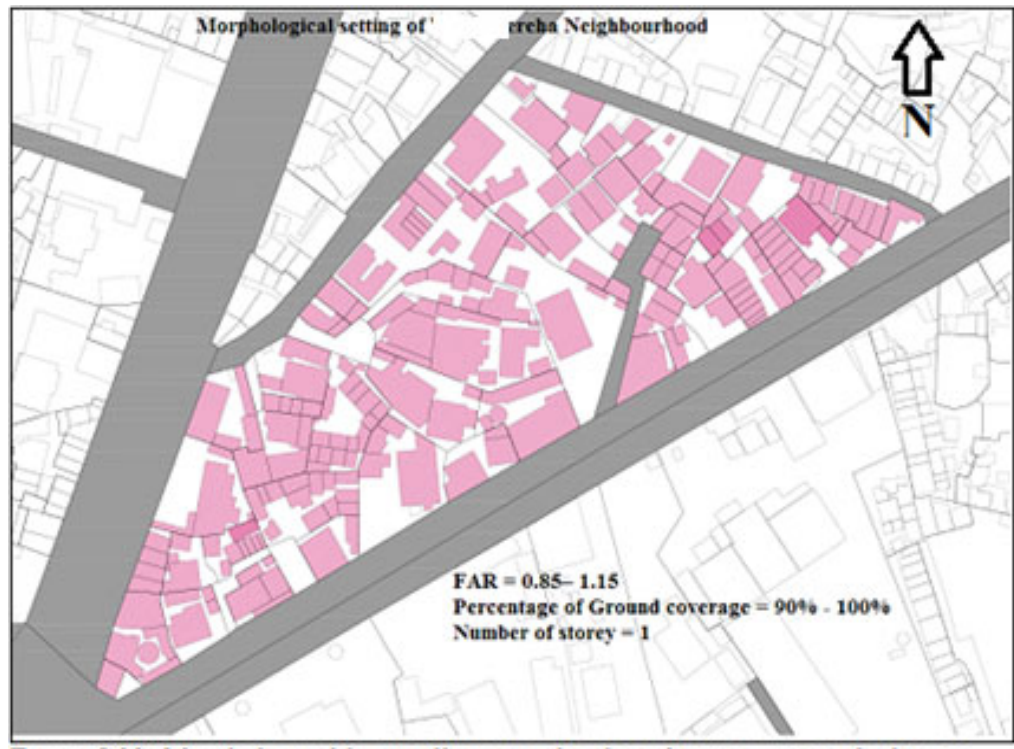

Figure 5.20 Morphological layout illus trates the close distance among the houses. outdoor spaces, green and open spaces, cross ventilation and provision of daylight inside the block are highly affected by the high ground coverage as high built-up density characteristics with low floor area ratio. High ground coverage against low floor area ratio is the characteristics of cities in developing countries like Addis Ababa that leads to less possibility of outdoor spaces, less access to mobility and circulation, create possibilities for incidence of crime, less opportunity to green and public urban spaces in the city. 
Table 6. Respondent Rated Opinions about Quality of Open Public Space in Their Neighborhood

\begin{tabular}{|c|c|c|c|c|c|c|c|c|c|c|c|c|}
\hline \multirow[b]{2}{*}{$\begin{array}{l}\text { Level } \\
\text { Agreement }\end{array}$} & \multicolumn{2}{|c|}{ Security } & \multicolumn{2}{|c|}{$\begin{array}{l}\text { Building Plot } \\
\text { Exposure }\end{array}$} & \multicolumn{2}{|c|}{$\begin{array}{l}\text { Front Set- } \\
\text { Backs }\end{array}$} & \multicolumn{2}{|c|}{ Shopping } & \multicolumn{2}{|c|}{$\mid \begin{array}{ll}\text { Social } & \\
\text { Services and } \\
\text { Facilities }\end{array}$} & \multicolumn{2}{|c|}{\begin{tabular}{|cr} 
Safety \& & Travel \\
Distance to \\
Services
\end{tabular}} \\
\hline & No. & $\%$ & No. & $\%$ & No. & $\%$ & No. & $\%$ & No. & $\%$ & No. & $\%$ \\
\hline Strongly Disagree & 367 & 75.5 & 29 & 6.0 & 62 & 12.8 & 25 & 5.1 & 287 & 59.1 & 330 & 67.9 \\
\hline Disagree & 95 & 19.5 & 368 & 75.7 & 371 & 76.3 & 385 & 79.2 & 97 & 20.0 & 64 & 13.2 \\
\hline No Difference & 1 & .2 & 21 & 4.3 & 9 & 1.9 & 36 & 7.4 & 9 & 1.9 & 53 & 10.9 \\
\hline Agree & & & $\ldots$ & $\ldots$ & 21 & 4.3 & 16 & 3.3 & 30 & 6.2 & $\ldots$ & $\ldots$ \\
\hline Strongly Agree & 23 & 4.7 & 68 & 14.0 & 23 & 4.7 & 24 & 4.9 & 63 & 13.0 & 39 & 8.0 \\
\hline Total & 486 & 100.0 & 486 & 100.0 & 486 & 100.0 & 486 & 100.0 & 486 & 100.0 & 486 & 100.0 \\
\hline
\end{tabular}

Source: Field Survey, 2018

As demonstrated in this study, unless open public spaces are properly planned, designed, maintained and managed they could reduce and further aggravate the existing poor urban image in the study area.

\section{Conclusions and Recommendations}

\subsection{Conclusions}

This study is conducted to evaluate quality of open public space in Addis Ababa based on conventionally agreed indicators. Though Addis Ababa is the seat of local international organizations as capital of Ethiopia and Africa, the city is not satisfying internationally accepted standards when evaluated from the point of open public spaces. Even if availability of various open spaces were confirmed, their quality is negatively assessed. Of total participants, $63 \%$ of them said that the existing quality of open public spaces is in bad conditions. Some $84 \%$ of respondents have mentioned that existing open public spaces are not pedestrian friendly. Respondent given reasons for bad quality of public open spaces primarily is because of poor management by government which is mentioned by $60 \%$ of participants. Indicators found as the measure of bad quality of public open spaces in this study are inadequate outdoor spaces, poor cross ventilation, poor accessibility, poor circulating spaces, unsatisfactory results in built up area ratio, and floor area ratio. Other dimensions of poor quality of open public spaces are related to security problems, building plot exposure front setbacks, shopping facilities, social services and facilities, safety and travel distance which all are negatively assessed.

According to both reported and observed information it could be understood that there are physically good and quality open spaces as Africa Park and the like which are not accessible in one hand and there are open spaces which are accessible but poor in their quality in the contrary. Poor quality open public spaces are a concern not only for repel their repulsive nature for visitors to them but they attract crime, hence the degree of crime prevalence is direct response to poor quality of neighborhood.

\subsection{Recommendations}

The research results and findings unveil that the Open Public Spaces have serious problems in terms of both physical and functional attributes showing poor quality of Open Public Spaces. In order to improve existing situation of open public spaces, the following recommendations are forwarded.

The city administration is strongly recommended to actively participate community to plantation and maintenance of trees at the streetscape and in front of their buildings with the guidance of proper experts. Efforts need to be exerted to capacitate community to the level of ownership to keep cleanness and protect open public spaces from illegal uses.

Poor quality of open public spaces is attributed to inadequacy of outdoor spaces, poor cross ventilation, poor accessibility, poor circulating spaces in open public spaces. Addressing these problems means adding values on the quality of open public spaces for which Addis Ababa City Administration is recommended.

Some planned and physically good parks like Africa Park should be accessible. Working for the quality of open public spaces should be a prior agenda to improve the image of the city and to satisfy the resident's as well as to make the city competitiveness at global level. Therefore, the city administration should ensure adequate funding, quality planning, sound implementation and management on the physical and functional aspects of open public spaces.

The study result revealed that there is lack of vista character among the connected roads to the public square. The road that radiate to the neighborhood and the road that leads to the Grand Palace side should be straight enough to enhance visual accessibility of the square. In addition to improving accessibility, pedestrian walkways that connect the open public places need to be enhanced by the city administration in collaboration with other stakeholders. Along with researchers strongly recommend the aesthetical as well as functional soft landscaping 
and hard landscaping to make the places comfortable for users.

Since crime is reported as an indicator of poor neighborhood, city administration should work to significantly improve prevalence of crime. The provision of amenities and activities suitable for the given place is strongly recommended to make the places attractive enough for their users. The appropriate coordination between open public spaces and other land uses shall continue to occur at each stage in the planning, design, development, and management process.

Availability of adequate spaces with good physical structure and their arrangements are among a good measure of quality neighborhood. Accordingly, Agency for Greenery and Beautification, the City Administration, Addis Ababa Municipality, and other concerned stakeholder of the city are recommended to satisfy such quality components in order to bring about quality open public spaces in Addis Ababa.

\subsection{Acknowledgements}

Researchers would like to thank Addis Ababa City Administration and respective sub-cities where data were collected from for their cooperation during data gathering. It gives researchers a great pleasure to extend thanks to research subjects of this study for their valuable time and knowledge. Special thanks also go to Ethiopian Civil Service University for financing this study.

\section{References}

Aljabri H., Smith H. (2013).Users' perceptions about planning and design of public open spaces: a case study of Muscat. Edinburgh, UK

Carmona M., Heath, T., Oc T. \& Tiesdell, S. (2003). Public Places - Urban Spaces: The Dimensions of Urban Design. Amsterdam, Architecture press.

Carmona, M. (2010). Contemporary Public Space: Critique and Classification. Part One: Critique. Journal of Urban Design,15(1) 123-148.

Commission for Architecture and the Built Environment (CABE-2004). The Values of Public Open Spaces: 1 Kemble street, London WC2B 4AN.

Larbi Touaf and Soumia Boutkhil (Ed.).(2008). The World as a Global Agora: Critical Perspective on Public Spaces. ISBN (10):1-4438-0000-7. Cambridge Scholars Publishing.

Llewelyn-Davies (2007). Urban Design Compendium-2. London, 110 Buckingham Palace Road, SW1W 9SA

Mare Addis Desta, etal (2015). Mapping of Plantation Forest in the Upper Catchment of Addis Ababa, International Journal of Environmental Sciences, Vol. 4 No. 3, 2015,pp. 158-165, ISSN: 2277-1948

Madanipour A. (2003). Public and Private Spaces of the City. London; NewYork. Routledge

Ministry of Works and Urban Development (2009). "My City" Youth Photo Competition, Addis Ababa, Ethiopia

QPS Sub Group: Leeds Chamber Property Forum (2008). 10 Key Principles to Good Quality Public Space. Available at: http://www.leeds.gov.uk/docs/CD12\%2028\%20QPS\%20Sub\%20group\%2010\%2 0prinicples\%20to\%20quality\%20public\%20space.pdf

UN habitat (2015).Global Public Space Toolkit: From Global Principles to Local Policies and Practice. ISBN Number: 978-92-1-132656-7.

Vahid Bigdeli Rad and Ibrahim Bin Ngah (2014). Vol. 26 No (1), P. 335-338. Assessment of Quality of Public Urban Spaces.University of Technology of Malaysia, Johor. sci.int, 